\title{
Synthesis, growth and characterization of semiorganic nonlinear optical single crystal bis(thiourea) barium nitrate (BTBN) for frequency conversion
}

\author{
A. Anbarasi ${ }^{1}$, S.M. Ravi Kumar ${ }^{2, *}$, M. Packiya Raj ${ }^{2}$, G.J. Shanmuga Sundar ${ }^{3}$, \\ M. GANAPATHY ${ }^{4}$, T. KUBENDIRAN ${ }^{2}$, S. VARALAKSHMI ${ }^{5}$ \\ ${ }^{1}$ P.G. \& Research Department of Physics, Periyar Government Arts College, Cuddalore-607001, Tamil Nadu, India \\ ${ }^{2}$ P.G. \& Research Department of Physics, Government Arts College, Tiruvannamalai-606603, Tamil Nadu, India \\ ${ }^{3}$ P.G. \& Research Department of Physics, Arigar Anna Government Arts College, Cheyyar-604 407, Tamil Nadu, India \\ ${ }^{4}$ P.G. \& Research Department of Chemistry, Government Arts College, Tiruvannamalai-606603, Tamil Nadu, India \\ ${ }^{5}$ Department of Physics, Kamban College of Arts and Science for Women, Tiruvannamalai-606601, Tamil Nadu, India
}

A novel semiorganic nonlinear optical (NLO) crystal, bis(thiourea) barium nitrate (BTBN) was synthesized and grown by slow evaporation method. Structure of the new crystalline compound was confirmed by single crystal X-ray diffraction analysis and it showed that BTBN belongs to orthorhombic crystal system. The crystalline nature of the BTBN was confirmed by powder X-ray diffraction study. Important functional groups of BTBN were identified by FT-IR spectroscopic analysis. UV-Vis-NIR spectral study showed that the grown crystal is transparent in the entire visible region with low cut off wavelength of $304 \mathrm{~nm}$. BTBN exhibits a SHG efficiency which is nearly 2.38 times higher than that of KDP. The BTBN crystal has high mechanical strength and belongs to soft category, which was confirmed by micorhardness study. The thermal stability of BTBN was determined from TGA and DTA thermal study which revealed that the BTBN crystal has thermal stability up to $243.1^{\circ} \mathrm{C}$. The surface properties and presence of elements was analyzed by SEM and EDAX study, respectively.

Keywords: crystal growth; semiorganic crystal; optical material; SHG; microhardness; TGA; DTA study

\section{Introduction}

The current research is focused on nonlinear optical (NLO) materials because of their vital applications in the field of optical modulation, optical switching, optical logic frequency shifting and optical data storage. It is the most interesting research field connected with the optical phenomena such as second harmonic generation (SHG) and third harmonic generation (THG). The emerging fields, such as telecommunication, signal processing, photonics and optoelectronics, are highly dependent on NLO materials [1-4]. Therefore, there is a challenge faced by materials scientists to discover new variety of NLO materials. In the recent past, many researchers have shown extreme interest in semiorganic crystals because

*E-mail: smravi78@ rediffmail.com of the combination of hyperpolarizability, low angular sensitivity, excellent mechanical properties and the ease to alter their molecular structure in order to maximize their nonlinear properties $[5,6]$. Generally, semiorganic NLO materials have better physical and chemical properties than their constituent elements and they are highly suitable to growing crystals with required dimensions [7, 8]. The literature shows that the research and development is focusing on a new class of NLO materials known as semiorganic materials $[9,10]$. In semiorganic material, polarizable organic molecules are stoichiometrically bound within an inorganic host. In fact, considerable efforts have been made to combine thiourea with various interesting inorganic matrices to produce materials having a noncentrosymmetric cell, large polarizability, and a strong nonlinear optical coefficient. When thiourea is combined with inorganic matrix it creates 
a semiorganic complex which has high optical nonlinearity and chemical flexibility of organics with the physical ruggedness of inorganics [11-13]. Ligands like thiourea and thiocyanate with $\mathrm{S}$ and $\mathrm{N}$ donors are capable of combining with metal to form stable complexes through coordinated bonds. Thiourea molecule is attracting not only due to the structural chemistry but also the attainability of formation of semiorganic coordination complexes which results in enhanced NLO activity [14, 15]. Thiourea based semiorganic optical crystals like potassium thiourea chloride (PTC) [16], calcium bis(thiourea) chloride (CBTC) [17], pure and magnesium doped ZTS [18], bis thiourea ammonium nitrate (BTAN) [19], cadmium thiourea acetate (CTA) [5], mono-thiourea cadmium sulfate dehydrate (MTCSD) [6] are good examples of engineering the materials with high nonlinearity out of an organic ligand with vanishing microscopic dipole moment (thiourea) by metal complexation, which exhibit very high NLO properties. Hence, our attention has been focused towards the development of semiorganic materials with thiourea ligand because of their interesting architecture and wide variety of applications. The thiourea complex of bis(thiourea) barium nitrate (BTBN) with dimension $16 \mathrm{~mm} \times 12 \mathrm{~mm} \times 4 \mathrm{~mm}$ has grown by solution growth method. The structural, spectral, optical, mechanical, thermal and surface properties of the grown BTBN have been investigated and discussed for the first time.

\section{Experimental}

\subsection{Synthesis}

Bis(thiourea) barium nitrate has been synthesized by taking AR grade thiourea and barium nitrate in stoichiometirc molar ratio 2:1. The synthesis process was done by using double distilled water at room temperature. The solution of BTBN was stirred using a magnetic stirrer for more than 6 hours to obtain a homogeneous solution. The synthesized compound of BTBN has been obtained by the following chemical reaction:

$2\left[\mathrm{CS}\left(\mathrm{NH}_{2}\right)_{2}\right]+\mathrm{Ba}\left(\mathrm{NO}_{3}\right)_{2} \rightarrow \mathrm{Ba}\left[\mathrm{CS}\left(\mathrm{NH}_{2}\right)_{2}\right]_{2}\left(\mathrm{NO}_{3}\right)_{2}$

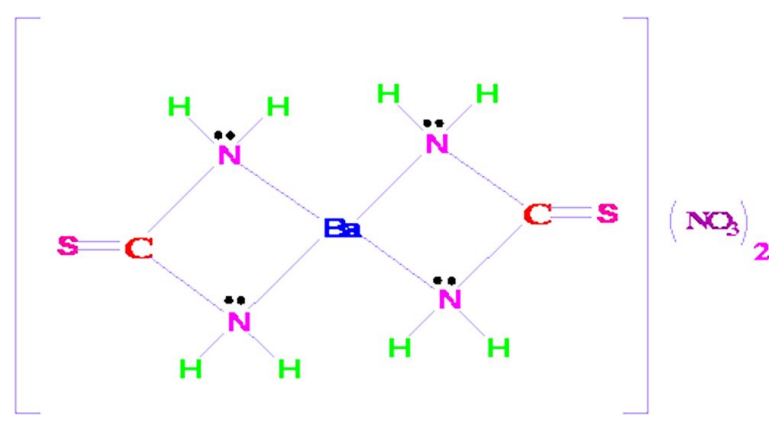

Scheme 1. Molecular arrangement of bis(thiourea) barium nitrate.

The International Union of Pure and Applied Chemistry (IUPAC) nomenclature of the compound is bis(thiourea) barium nitrate. In this complex, the ligand thiourea acts as monodentate ligand. Since the coordinate bond is formed between the barium and sulfur atom present in thiourea molecule, the thiourea molecule acts as a negative ligand through sulfur atom which is mentioned in the following resonating structure by the formation of zwitter ion.

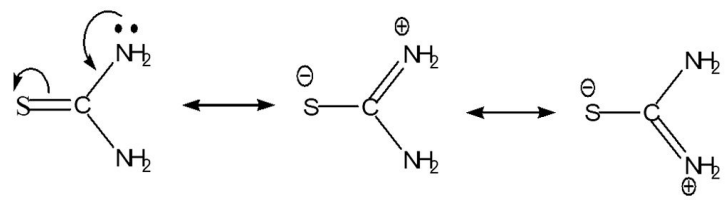

Scheme 2. The molecular structure of thiourea.

In this complex, the coordinate bond is formed between the central barium atom and sulfur atom of thiourea. The bond cannot be formed between the barium atom and lone pair of electron of nitrogen atom which clearly shows the stretching frequencies of $\mathrm{C}-\mathrm{S}$ and free $\mathrm{NH}_{2}$ and $\mathrm{NH}_{2}^{+}$. The molecular structure of bis(thiourea) barium nitrate is shown in Scheme 1.

\subsection{Solubility}

The solubility of BTBN in double distilled water was measured at five different temperatures $\left(30{ }^{\circ} \mathrm{C}, 35^{\circ} \mathrm{C}, 40{ }^{\circ} \mathrm{C}, 45^{\circ} \mathrm{C}\right.$ and $\left.50{ }^{\circ} \mathrm{C}\right)$. The solubility data were determined by dissolving the synthesized salt of BTBN in $100 \mathrm{~mL}$ of double distilled 
water at a constant temperature under continuous stirring. After attaining saturation, the equilibrium concentration of the solute was analyzed gravimetrically. The solubility of BTBN increased with temperature and thus exhibited positive solubility coefficient. The solubility curve for BTBN is shown in Fig. 1.

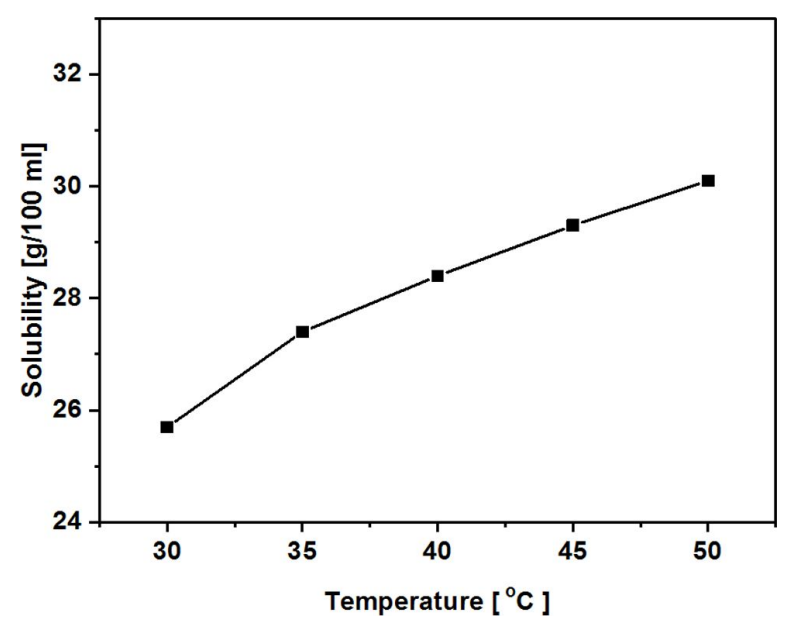

Fig. 1. Solubility curve of BTBN.

\subsection{Crystal growth}

The saturated solution bis(thiourea) barium nitrate was filtered using good quality microfilter paper to remove the insoluble impurities. The filtered solution was transferred into a beaker and sealed with a plastic sheet with few holes. The beaker was kept in an undisturbed and dust free environment. After the time period of 20 days the tiny seed crystals were obtained. Macroscopic, defect free transparent crystals were selected as seed for growing large size single crystal of BTBN. The seed crystal was introduced into the mother solution. The crystal was grown as a bulk crystal with dimension $16 \mathrm{~mm} \times 12 \mathrm{~mm} \times 4 \mathrm{~mm}$ in the period of 35 to 45 days. The as-grown crystal of BTBN is shown in Fig. 2.

\section{Results and discussion}

\subsection{Single crystal XRD studies}

The single crystal XRD studies have been carried out to confirm the crystallinity and

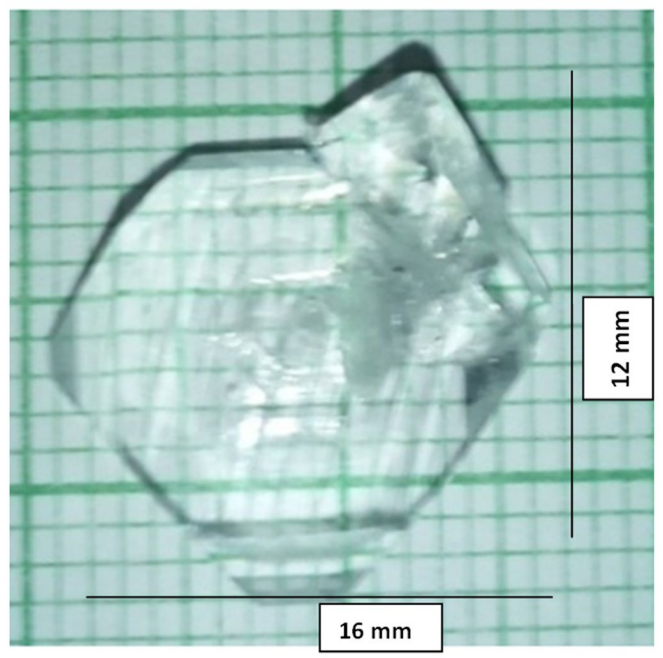

Fig. 2. Photograph of as-grown crystal of BTBN.

to measure the lattice parameter of the grown crystal. The single crystal XRD study has been performed using ENRAF NONIUS CAD4 X-ray diffractometer. The calculated cell parameters are $\mathrm{a}=5.1310 \AA, \mathrm{b}=7.0907 \AA, \mathrm{c}=8.1131 \AA, \alpha=\beta$ $=\gamma=90^{\circ}$ and $\mathrm{V}=352.838 \AA^{3}$. By comparing the cell parameters of thiourea and bis(thiourea) barium nitrate, one can understand the role of barium nitrate in the grown crystal. The comparison of cell parameters of thiourea and the grown BTBN sample is given in Table 1. From the result it is observed that the structure of the thiourea has not changed whereas the values of cell parameters have varied which confirms the incorporation of barium nitrate into the thiourea. The grown crystal belongs to an orthorhombic crystal system with noncentrosymmetric space group $\mathrm{P}_{21}$.

\subsection{Powder XRD analysis}

The grown crystal of BTBN was ground into fine powder form to investigate its crystalline nature by powder X-ray diffraction analysis using BRUCKER, (Model D8 Advanced, Germany) $\mathrm{X}$-ray diffractometer with $\mathrm{CuK} \alpha$ radiation (wavelength $1.5405 \AA$ ). The obtained XRD pattern shows the sharp Bragg peaks which reveal the high crystalline nature of BTBN. The recorded powder XRD pattern of BTBN is depicted in Fig. 3. 
Table 1. Comparisons of lattice parameters with BTAN.

\begin{tabular}{llllll}
\hline Sample & $\mathrm{a}[\AA]$ & $\mathrm{b}[\AA]$ & $\mathrm{c}[\AA]$ & Volume $\left[\AA^{3}\right]$ & Crystal system \\
\hline \hline Thiourea & 7.655 & 8.537 & 5.520 & 360.732 & Orthorhombic \\
BTBN $^{*}$ & 5.1310 & 7.0907 & 8.1131 & 352.838 & Orthorhombic \\
\hline
\end{tabular}

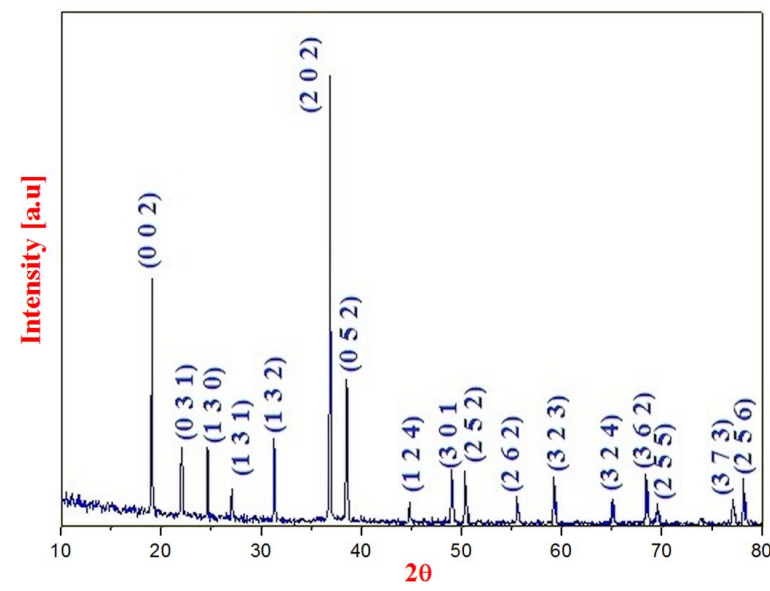

Fig. 3. The powder XRD pattern of BTBN crystal.

\subsection{FT-IR spectral studies}

The grown crystal of BTBN was subjected to Fourier Transform Infrared (FT-IR) spectroscopy analysis using Perkin Elmer Spectrum RX1 Fourier transform infrared spectrometer. The FT-IR spectrum of the BTBN crystal is shown in Fig. 4. The spectrum confirms the presence of important functional groups in the BTBN. The obtained functional groups with corresponding wave numbers are given in Table 2. Investigations of crystal structure of thiourea have established the co-planar structure of $\mathrm{C}, \mathrm{N}$ and $\mathrm{S}$ atoms in the molecule. The broad and intense peak due to $\mathrm{N}-\mathrm{H}$ stretching vibration appeared as a strong absorption band in the region of $3429 \mathrm{~cm}^{-1}$. The shifting of lower frequency gives information about the formation of metal thiourea complex which indicates that the bonding is only between sulfur and nitrogen atoms. The peak observed at $2815 \mathrm{~cm}^{-1}$ is due to O$\mathrm{H}$ stretching vibration. The $\mathrm{NH}_{2}$ stretching is observed at $2742 \mathrm{~cm}^{-1}$. The $\mathrm{C}-\mathrm{N}$ symmetric stretching has occurred at $2098 \mathrm{~cm}^{-1}$. At $1779 \mathrm{~cm}^{-1}$, the $\mathrm{N}-\mathrm{H}$ bending vibration is detected. The $\mathrm{NH}_{2}$ rocking vibration is obtained at $1446 \mathrm{~cm}^{-1}$. The low shift of $\mathrm{C}=\mathrm{S}$ stretching frequency $\left(740 \mathrm{~cm}^{-1}\right.$ to $720 \mathrm{~cm}^{-1}$ ) confirms the formation of metal sulfur coordination bond [20].

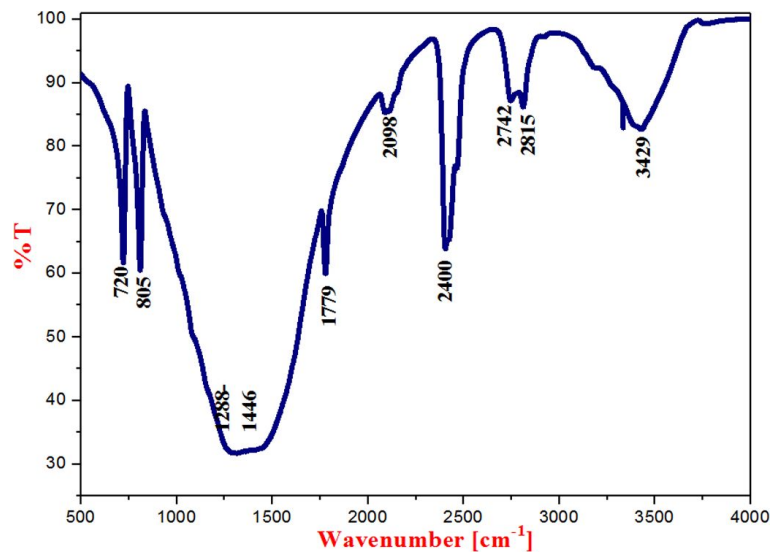

Fig. 4. FT-IR spectrum of BTBN crystal.

\subsection{Optical transmission studies}

The most important property of nonlinear optical crystal is wide transparency window which can be analyzed by optical transmission study using UV-Vis-NIR spectrophotometer. Therefore, determination of transmittance is very important for a crystal to recognize its suitability for optical applications. The optical transmission spectrum was recorded using DOUBLE BEAM UV-Vis spectrophotometer 2202 in the region of $200 \mathrm{~nm}$ to $1100 \mathrm{~nm}$. The spectrum is shown in Fig. 5. From the spectrum, it is observed that the grown crystal has low cut off wavelength around $304 \mathrm{~nm}$ and good transparency in UV as well as visible regions (304 $\mathrm{nm}$ and $1100 \mathrm{~nm}$ ). The absence of absorption in the region between $304 \mathrm{~nm}$ and $1100 \mathrm{~nm}$ indicates that the grown crystal could be used for optical window applications. The wide range of transparency of the grown crystal is an additional advantage in the field of optoelectronic applications. The optical band gap of the grown BTBN crystal was 
Table 2. Assignment of IR band frequencies $\left(\mathrm{cm}^{-1}\right)$ of thiourea and BTBN.

\begin{tabular}{ccl}
\hline Thiourea $\left[\mathrm{cm}^{-1}\right]$ & BTBN $\left[\mathrm{cm}^{-1}\right]$ & Assignments \\
\hline \hline 3376 & 3429 & $\mathrm{~N}-\mathrm{H}$ stretching vibration \\
2851 & 2815 & $\mathrm{O}-\mathrm{H}$ stretching vibration \\
- & 2742 & $\mathrm{NH}_{2}$ stretching \\
2075 & 2098 & $(\mathrm{C}-\mathrm{N})$ symmetric \\
1627 & 1779 & $\mathrm{~N}-\mathrm{H}$ bending vibration \\
1429 & 1446 & $\mathrm{NH}_{2}$ rocking vibration \\
792 & 805 & $(\mathrm{C}=\mathrm{S})$ symmetric stretching \\
730 & 720 & $(\mathrm{C}=\mathrm{S})$ stretching vibration \\
\hline
\end{tabular}

determined by plotting the Tauc plot (Fig. 6) and from the graph it was found to be $3.85 \mathrm{eV}$.

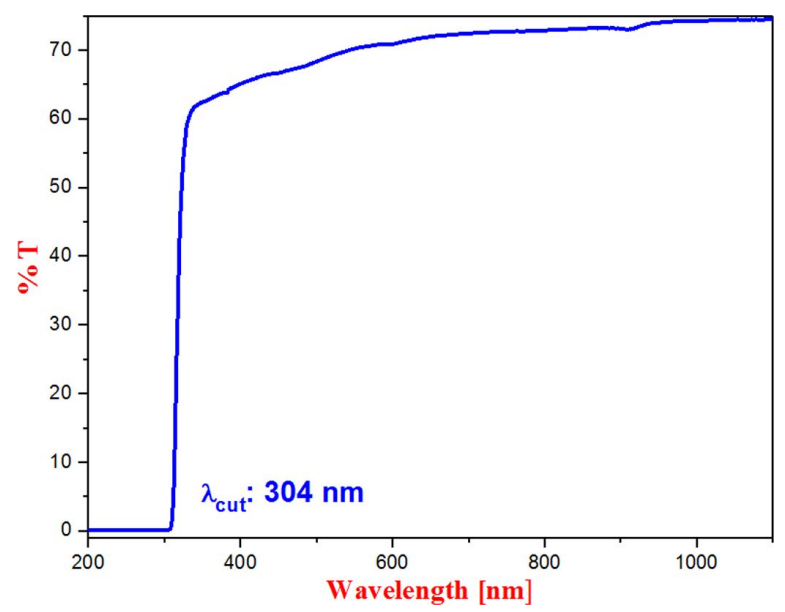

Fig. 5. UV-Vis-NIR spectrum of BTBN crystal.

\subsection{Microhardness studies}

The microhardness study is a suitable technique to identify the mechanical behavior of a sample and it reveals the worthiness of the sample for device fabrication. Hence, the grown crystal of BTBN (with a thickness of $2 \mathrm{~mm}$ ) was subjected to hardness test by using Shimadzu HMV microhardness tester fitted with a diamond pyramidal indenter. Hardness values were measured for different magnitudes of load varying from $10 \mathrm{~g}$ to $50 \mathrm{~g}$. The value of $\mathrm{Hv}$ decreases with increasing the load as is shown in the Fig. 7. The calculated hardness values are $90.8 \mathrm{~kg} / \mathrm{mm}^{2}, 78.4 \mathrm{~kg} / \mathrm{mm}^{2}$, $70.4 \mathrm{~kg} / \mathrm{mm}^{2}, 67.2 \mathrm{~kg} / \mathrm{mm}^{2}$ for the applied load

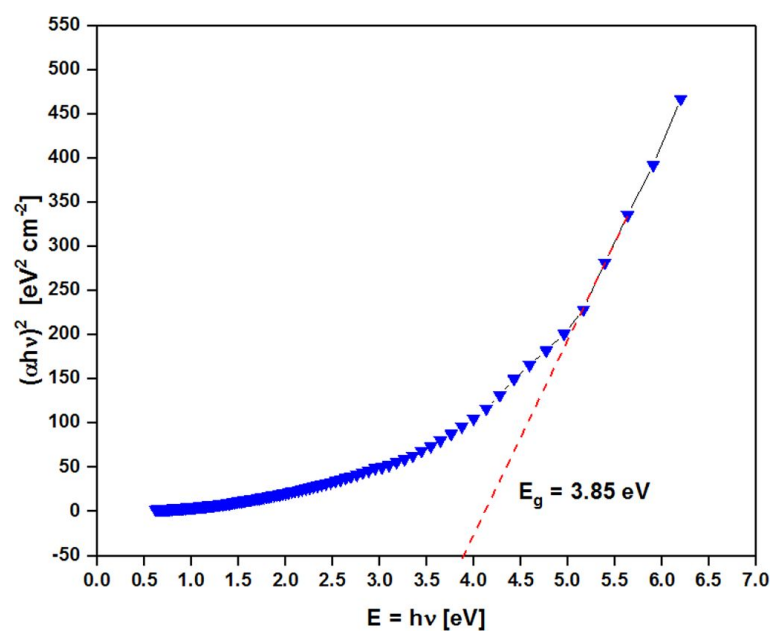

Fig. 6. Tauc plot of BTBN crystal.

of $10 \mathrm{~g}, 25 \mathrm{~g}, 50 \mathrm{~g}$, respectively. The result implies that the BTBN crystal could be mechanically stable up to $50 \mathrm{~g}$ and then the crack is observed on the surface of the crystal. To analyze the soft/hard nature of the grown crystal, the graph between log p vs. $\log \mathrm{d}$ has been drawn (Fig. 8). From the slope of linear part of the plot fitted with a straight line, the value of $n$ for selected plane can be obtained. The measured value of $\mathrm{n}=1.651$ indicates that the grown sample of BTBN belongs to soft category.

\subsection{TG and DTA studies}

Thermal behavior of the BTBN crystal was analyzed by the thermogravimetric analysis (TGA) and differential thermal analysis (DTA) using an instrument Netszch STA 409C. The sample was heated in a crucible between the temperature 


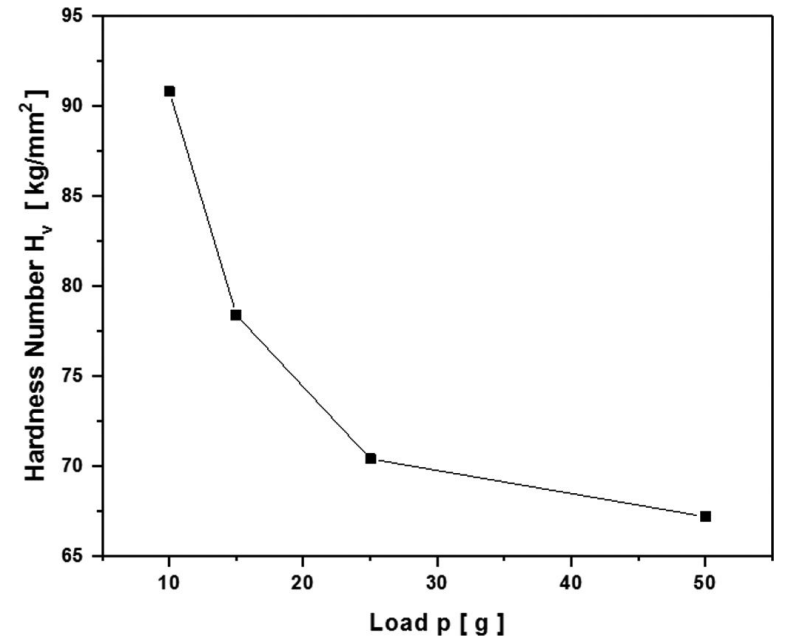

Fig. 7. Variation of Hv versus load $\mathrm{p}$ for BTBN crystal.

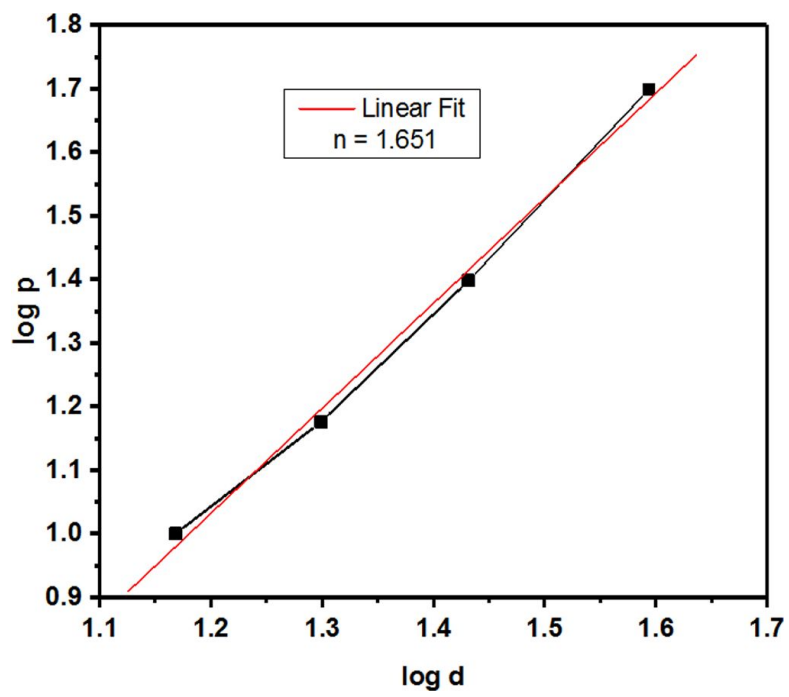

Fig. 8. Plot of $\log p$ vs. $\log d$ for BTBN single crystal.

of $50{ }^{\circ} \mathrm{C}$ and $1200{ }^{\circ} \mathrm{C}$ at a heating rate of $20^{\circ} \mathrm{C} / \mathrm{min}$ in nitrogen atmosphere. The TGA-DTA curves of the BTBN crystal are shown in Fig. 9. The grown sample has four stages of decomposition which have been determined from the thermogram of the BTBN. During the first stage, the maximum weight loss of BTBN occurs at $243.1{ }^{\circ} \mathrm{C}$, which is attributed to the removal of hydrogen from the thiourea molecule. The second stage of decomposition occurs at a temperature of $261.2{ }^{\circ} \mathrm{C}$, corresponding to the removal of nitrogen from the thiourea molecule. The third stage of decomposition temperature occurs at $333.1{ }^{\circ} \mathrm{C}$, which is due to removal of carbon from the thiourea molecule. The fourth stage of decomposition indicates the breaking of sulfur-barium coordination bonds $\left(390{ }^{\circ} \mathrm{C}\right)$. The total weight loss in these four stages was found to be $54 \%$, which was due to the removal of two units of thiourea molecule. The final stage peak at $756.0{ }^{\circ} \mathrm{C}$ was due to the melting of $\mathrm{BaNO}_{3}$. After the final stage of decomposition up to $1200{ }^{\circ} \mathrm{C}$, the residual material was found to be barium. The total weight loss of pure BTBN was found to be $83 \%$.

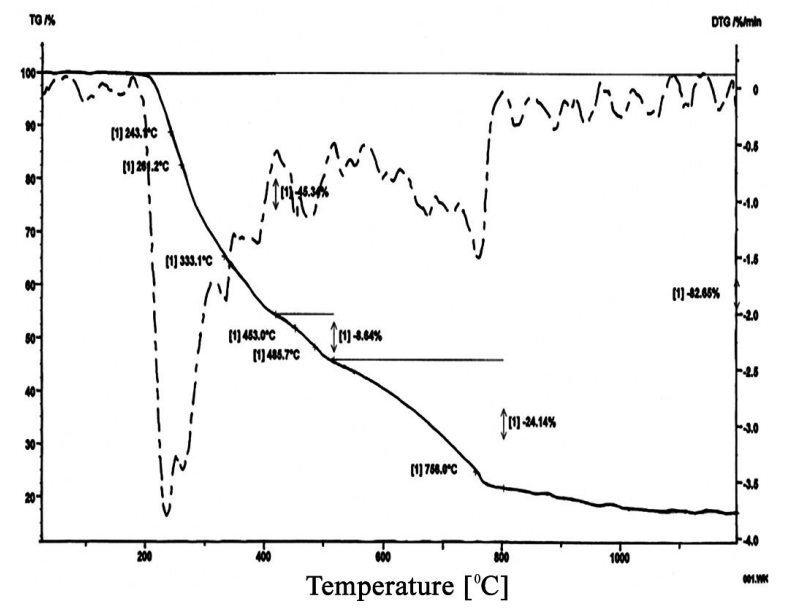

Fig. 9. TG/ DTA curve of BTBN crystal.

\subsection{Second harmonic generation (SHG) analysis}

The second harmonic generation (SHG) efficiency was measured for a grown BTBN crystal using the well-known technique of Kurtz et al. [21]. The sample was ground into powder form and packed between the transparent slides. The incident light with a wavelength of $1064 \mathrm{~nm}$ from the source of Q-switched Nd:YAG laser with a power density $1 \mathrm{GW} / \mathrm{cm}^{2}$ and pulse width $8 \mathrm{~ns}$ of repetition rate $10 \mathrm{~Hz}$ was passed through the packed powdered sample. The sample emitted bright green light $(532 \mathrm{~nm})$ which confirmed the second harmonic generation. To compare the SHG efficiency with a commercial NLO crystal, potassium dihydrogen phosphate (KDP) was taken as a reference material. The KDP crystal was ground to obtain the identical particle size as the studied sample 
and the same procedure was done. The SHG efficiency results for both the grown and reference sample are given in the Table 3. From the results, we observed that the output energy of the grown BTBN crystal is 2.38 times greater than that of KDP. Hence, the BTBN crystal may replace the commercial NLO crystal in photonics, optoelectronics and laser field. The result of SHG efficiency of grown sample compared with a known NLO crystal is given in Table 4 .

\subsection{SEM studies}

The morphology and orientation of the sample were identified using scanning electron microscope (SEM). The surface pitting, deposits of dust and contaminant particles and filter residues were also assessed. The SEM analysis was carried out using JEOL/E O-JSM-5610. The SEM photograph of a grown BTBN crystal is shown in Fig. 10. From the figure, it is observed that the surface of the crystal has few dislocations and voids which may be the common phenomenon of solvent inclusion in solution grown crystals.

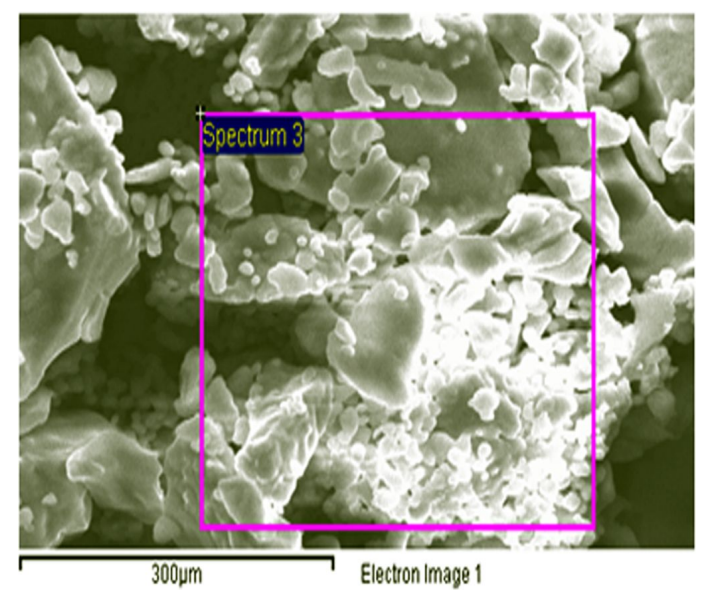

Fig. 10. SEM photograph of BTBN crystal.

\subsection{EDAX analysis}

To confirm the presence of metal elements in the grown sample, energy dispersive atomic $\mathrm{X}$-ray fluorescence spectrometry (EDAX) has been carried out. The EDAX spectrum of BTBN crystal is shown in the Fig. 11. From the spectrum,

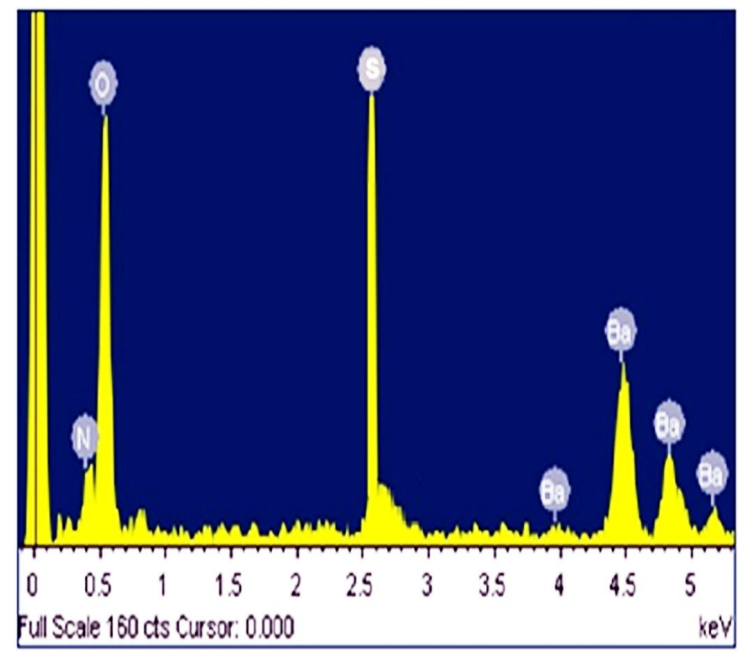

Fig. 11. EDAX spectrum of BTBN crystal.

it is observed the presence of barium; an important functional element in the sample of thiourea is sulfur.

\section{Conclusion}

Good quality nonlinear optical semiorganic single crystals of BTBN have been successfully synthesized. The crystals were grown by solution growth technique using double distilled water as a solvent. Single crystal study revealed that the grown crystal belongs to orthorhombic crystal system. Good crystalline nature and intensity variations were observed in powder X-ray diffraction study. FT-IR spectroscopic analysis confirmed the functional group and molecular structure of the compound. The transparency of the crystal in the visible and infrared regions between $304 \mathrm{~nm}$ and $1100 \mathrm{~nm}$ was deduced from the transmission spectrum and it confirms the NLO properties of the crystal. It has low UV cutoff of $304 \mathrm{~nm}$ and good transmittance. The mechanical strength of the crystal has been studied by Vickers microhardness measurement which indicated that the hardness number in the crystal decreases with the applied load. The BTBN crystal was found to be thermally stable up to $243.1{ }^{\circ} \mathrm{C}$. The SHG efficiency of the BTBN is 2.38 times greater than that of the reference material KDP. The surface morphology and the presence of barium was investigated by SEM/EDAX study. 
Table 3. SHG efficiency the grown and reference material.

\begin{tabular}{lcc}
\hline \multicolumn{1}{c}{ Name of the sample } & Input energy $[\mathrm{mJ}]$ & Output energy $[\mathrm{J}]$ \\
\hline \hline Potassium dihydrogen phosphate KDP & 0.68 & 7.80 \\
Bis(thiourea) barium nitrate (BTBN) & 0.68 & 18.6 \\
\hline
\end{tabular}

Table 4. Comparison of SHG efficiency of the grown sample with other thiourea complex semiorganic crystals.

\begin{tabular}{clcl}
\hline \multirow{2}{*}{ S. No. } & \multirow{2}{*}{ Name of the crystal } & $\begin{array}{c}\text { SHG efficiency relative to } \\
\text { KDP }\end{array}$ & \multicolumn{1}{c}{ Literature } \\
\hline \hline 1. & Bis(thiourea) zinc chloride (BTZC) & 1.75 & Parasuraman et al. [22] \\
2. & Bis(thiourea) zinc acetate (BTZA) & 2.0 & Nirmala et al. [13] \\
3. & Thiourea potassium hydrogen phthalate (TKHP) & 1.2 & Srinivasan et al. [23] \\
4. & Bis(thiourea) strontium chloride (BTSC) & 1.54 & Rajagopalan et al. [24] \\
5. & Bis(thiourea) ammonium nitrate (BTAN) & 1.52 & Anbarasi et al. [19] \\
\hline
\end{tabular}

\section{Acknowledgements}

The authors thank the B.S. Abdur Rahman University, Vandalur, Chennai, for providing instrument facility for characterization and the National College, Trichy, for providing the EDAX spectrum. The corresponding author thankfully acknowledge the Science and Engineering Research Board (SERB), Department of Science and Technology (DST), for the financial support for Project (FILE NO. $\mathrm{EEQ} / 2016 / 000451)$.

\section{References}

[1] Ledou X., Synth. Mat., 54 (1993), 123.

[2] Yuan D.R., Xu D., Zhang N., LiU M.C., JiAng M.H., Chinese Phys. Lett., 13 (1996), 841.

[3] Iwai M., Kobayashi T., Furya H., Mori Y., SASAKI T., Jpn. J. App. Phys., 36 (1997), 276.

[4] Wang X.Q., XU D., Yuan D.R., Tian Y.P., YU W.T., SUn S.Y., YANG Z.H., FANG Q., LU M.K., Yan Y.X., Meng F.Q., GuO S.Y., Zhang G.H., JiANG M.H., Mater. Res. Bull., 34 (2003), 199.

[5] Azar S.M., Mohd Anis, Hussaini S.S., KAlainathan S., ShIRSAT M.D., RABBANI G., Opt. Laser Technol., 87 (2017), 11.

[6] Sivanandan T., Kalainathan S., Mater. Chem. Phys., 168 (2015), 66.

[7] Kim P.J., Jazbinsek M., Kwon O.P., Cryst. Growth Des., 11 (2011), 3060.

[8] Felicita J., Vimal A., Thomas Joseph Prakash, Spectrochim. Acta Part A, 107 (2013), 371.

[9] Muhammad S., Xu H., Liao Y., Kan Y., Su Z., J. Am. Chem. Soc., 42 (2013), 15053.

[10] Shkir M., Muhammad S., Alfaify S., Spectrochim. Acta Part A, 143 (2015), 128.

[11] Pabitha G., Dhanasekaran R., J. Cryst. Growth, 362 (2013), 259.
[12] Kanagasabapathy K., Rajasekaran R., Optik, 124 (2013), 4240.

[13] Ruby Nirmala L., Thomas Joseph Prakash J., Spectrochim. Acta Part A, 97 (2012), 673.

[14] Sankar R., Raghavan C.M., Mohan Kumar R., JAYAVEl R., J. Cryst. Growth, 305 (2007), 156.

[15] Ravi Kumar S.M., Melikechi N., Selvakumar S., Sagayaraj P., Physica B, 403 (2008), 4160.

[16] Raju S., Muralidharan R., Krishnan H., Optik, 127 (2016), 3620.

[17] Mohd Anis, Hussaini S.S., HaKeem A., Shirsat M.D., Muley G.G., Optik 127 (2016), 2137.

[18] Sumithra Devi M., Arthi A.P., ThamizhaRASAN K., Superlattice. Microst., 73 (2014), 296.

[19] Anbarasi A., Ravi Kumar S.M., Shanmuga Sundar G.J., Allen Moses M., Packiya Raj M., Parabhakaran M., Ravisankar R., GunaseeLAN R., Physica B, 522 (2017), 31.

[20] Swaminathan, H.M.N.H. IRVing, J. Inorg. Nucl. Chem., 26 (1964), 1291.

[21] Kurtz S.K., Perry T.T., J. Appl. Phys., 39 (1968), 3798.

[22] Parasuraman K., Sakthi Murugesan K., Uthrakumar R., Jerome das J., Milton Boaz B., Physica B, 406 (2011), 3856.

[23] SRinivasan R., Anbarasi A., Revathi T., Ravi Kumar S.M., Mater. Chem. Phys., 177 (2016), 25.

[24] RajagopalaN K., KRISHNAMOORTHY P., JAYAMOORTHY K., Muthu Austeria, Karbala Int. J. Mod. Sci., 2 (2016), 219. 